\section{Nuclear risk assessment}

SIR-I write about the letter of S. Islam and $\mathrm{K}$. Lindgren ${ }^{1}$. Exposure to nuclear accidents and the question whether nuclear engineering is safe or not, and to what degree, is not a question to be answered by sterile theory. The life, health and general well-being of many depend on the availability of cheap and comparatively safe energy. If silly calculations exaggerate the problems caused by mass hysteria, this is not in the best interest of an advanced technological society.

The conclusions reached by Islam and Lindgren are not only wrong but, worse, misleading for those such as the Greens in West Germany. Here are some obvious flaws.

(1) The authors write that "risk assessments which use data from operating experience are a must". I wish they had followed their own advice. What did they do? They inserted the operating experience (reactor years) of a very mixed sample and two accidents (Three Mile Island and Chernobyl) into some formulae. On such a basis, a hypothetical assessor of earthquake catastrophes would have entered an observation period of 10 years at the time when Shakespeare wrote King Henry $V I$, ten to eleven years after the "London Earthquake", Isaac Newton would have used 107 years when his Philosophiae naturalis principia mathematica was published and R.A. Fisher would have taken 470 years in 1950 . One may repeat this Gedankenexperiment in relation to the catastrophic earthquakes of 1811-12 south of St Louis, Missouri. The authors should also ask themselves what their exposure calculations would have produced had the London or the Missouri earthquakes not occurred.

Backed by decades of risk assessment and using the very extensive data of the two largest reinsurance companies, I can assure the authors that a realistic probabilistic evaluation of the catastrophe potential is possible only if one has plenty of information on all accidents, from the smallest to the very largest; only then can reliable probability distributions be inferred

(2) The authors have (generously) not counted the Windscale accident of 1957 "because it was a military reactor". What matters is the type and the parameters of a reactor, not whether it is a private or a military reactor.

(3) It is obviously unknown to the authors how large the difference is between Soviet RMBK-1000 reactors, light-water moderated reactors and other types. Accident probability depends not only on such basic differences but on engineering details, quality control and on hazards such as fire, explosion, earthquake, flood and so on, and on human parameters. No greengroc- er would conclude from an observational sample of thousands of banana and strawberry-years that he must also sell his coconuts and almonds within a day or so to reduce loss from deterioration. Calculations that lump all types of reactors into one sample are not worth taking seriously.

Risk assessment segregates the total exposure according to parameters controlling accidents, when it is possible to correlate actual damage experience with individual parameters to find out which of them appears to be important, whether the list is complete and how much information on accidents is available. More advanced methods ( $c f$. ref. 2) but even comparatively simple stochastic calculations, will show that a very large number of observations is necessary per subsample to produce reliable results.

Regretfully, I must add that I know of only a few cases where planners, designers, engineers or contractors of large and risky projects have consulted those with the largest collection of data on accidents and damage (such as specialized insurers and reinsurers).

Unfortunately, it is not generally realized that mathematical models, hypothetical reasoning or thinking carefully about accidents, using logically plausible scenarios $^{3}$ and subtleties such as wondering whether to use Poisson, Pearson, Weibull or Gumbel III, are no cheap substitute for difficult, time-consuming and costly compilations of information on actual failures. The observed failure frequency of civil engineering structures, for example, is several orders of magnitude greater than the safety to be expected from calculations ${ }^{4}$. How large is the error margin if far more exotic projects are designed according to logical, albeit theoretical scenarios?

\section{Stefan-Rotthaler-Str. 5}

Herbert Tiedemann

\section{D-8052 Moosburg, FRG}

1. Islam, S. \& Lindgren, K. Nature 322, 691-92 (1986) Wald, A. Sequential Analysis (Wiley, New York, 1947). Wilson, R. Nature 322, 768 (1986)

4. Rybicki, R. Schäden und Mängel an Baukonstruktionen, 10 (Werner, Düsseldorf 1972)

\section{Avalanche dowsing}

Sir-I am grateful to Nature for publishing accounts of the scientific status of the shadowy field of paranormal phenomena, an area most serious scientists deliberately ignore.

The Norwegian Red Cross Mountain Rescue Organization officially advocates dowsing as an effective method for finding victims of avalanches. This voluntary organization has about 5,000 members in the mountains during the Easter skiing season. Dowsing has been taught for more than 10 years, under the pretence that the technique is accepted by mountain rescue organizations in other countries. Dowsing exercises have been part of the avalanche safety course taught to career officers of the Norwegian Army, and dowsing rods are part of the Army equipment for avalanche rescue.

On 5 March 1986, 16 young Norwegian soldiers died in an avalanche at Vassdalen in northern Norway. Dowsing was attempted by an Army officer in an area where seven or eight soldiers were later found dead. He got between 20 and 30 signals, of which one or possibly two pointed to a victim. He attributes the poor result to the presence of water and vegetation under the snow but is convinced the technique would work under other conditions. A central representative of the Red Cross has expressed the opinion that the dowser was not sufficiently familiar with the technique. The two positive finds made by dowsers at accidents in snow can both be associated with external visual clues. The results are thus in line with those presented, for example by Foulkes ${ }^{1}$ and $\mathrm{Marks}^{2}$, that in the absence of such clues the outcome of dowsing is no better than a series of guesses.

Fortunately, dowsing at the Vassdalen catastrophe did not interfere with the regular search activities which took place simultaneously.

Dowsing is not accepted by the Norwegian police and the Norwegian Geotechnical Institute, responsible for scientific studies of avalanches in this country, has taken a firm stand against the technique.

Rolf Manne

Department of Chemistry,

University of Bergen,

$N-5000$ Bergen,

Norway

1. Foulkes, R.A. Nature 299, 163-168 (1971)

2. Marks, D.F. Nature 320, 119-124 (1986).

\section{Wrong dose}

SIR-In your recent article "Occupational radiation: British nuclear workers cleared" (Nature 323, 481; 1986), there was a major error. It was reported that for Sellafield workers, "the average radiation dose for those for whom film badge records are available is given as $124 \mathrm{mSv}$ (12.4 mrem) accumulated until the end of 1983". Which dose is correct? A dose of $124 \mathrm{mSv}$ is equal to $12.4 \mathrm{rem} .12 .4 \mathrm{mrem}$ is equivalent to a dose of $124 \mu \mathrm{Sv}$. There is a large difference between 12.4 mrem and $12.4 \mathrm{rem}$.

T.L. KELLOGG

University of Vermont

Radiological Safety Office,

004 Rowell Building,

Burlington, Vermont 05405, USA

- The smaller dose was that intended. Editor, Nature. 